\title{
Human Plasma and the Antibacterial Effect of Peritoneal Dialysis Solutions
}

\author{
KENNETH A. BORCHARDT, JAMES A. RICHARDSON
}

British Medical fournal, 1971, 1, 205-206

\section{Summary}

The influence of human plasma on the antibacterial effect of solutions for peritoneal dialysis was studied. The solutions contained $43 \mathrm{mEq}$ per litre of either acetate or lactate as the source of base. Enough pooled human plasma was added to half of each solution to give a total concentration of a gramme of protein per litre. The numbers of viable organisms from 15 clinical isolates each of Staphylococcus aureus, Escherichia coli, and Pseudomonas species were counted before and after incubation in the four solutions. Numbers of viable Staph. aureus and $E$. coli diminished consistently after incubation in all four solutions, but the greatest decreases occurred in the acetate solution which contained no plasma. Plasma abolished the greater antibacterial effect of acetate on these organisms. Differences between numbers of viable Pseudomonas sp. after incubation in the four solutions were not significant. The diffusion of substances from plasma into dialysis fluids during peritoneal dialysis, therefore, may abolish the greater antibacterial effect of solutions made with acetate rather than lactate.

\section{Introduction}

In earlier work peritoneal dialysis solutions made with acetate rather than with lactate were shown to have a greater antibacterial effect on pathogenic Staphylococcus aureus, Escherichia coli, and Pseudomonas species (Richardson and Borchardt, 1969). This effect was independent of differences in $\mathrm{pH}$ of the solutions and seemed to result from substitution of the acetate anion for the lactate anion. Incubation in the acetate solutions was particularly toxic to Staph. aureus, least so to Pseudomonas sp. The antibacterial effect gave hope that dialysate made with acetate would provide greater protection against peritonitis. The system in which the effect was confirmed, however, had no source of the nitrogen necessary for bacterial growth. During actual dialysis sources of nitrogen, such as plasma proteins and amino-acids, diffuse into the dialysate in the peritoneal space. These substances could negate the greater antibacterial effect of acetate or even create a good culture medium. The experiment reported here tested the influence of human plasma on the antibacterial effect of dialysates made with acetate and lactate.

\section{Methods}

Four different solutions were made from distilled water and reagent grade chemicals. Final measurements of salts and glucose in the solutions were similar. The $\mathrm{pH}$ of the solutions made with lactate $(5.3)$ was adjusted to that of the solutions made with acetate (6.8) by substituting about $2 \mathrm{mEq}$ of Public Health Service Hospital, San Francisco, California 94118,
U.S.A.

KENNETH A. BORCHARDT, PH.D., Chief, Microbiology Service

JAMES A. RICHARDSON, M.D., F.A.C.P., Chief, Renal Service hydroxide (as sodium hydroxide) per litre for a similar quantity of chloride. The salts of the dialysate solutions were brought to almost full dilution with water. Venous blood was collected from five normal volunteers into plastic bags containing heparin. Plasma was removed by centrifugation and equal amounts from each subject were pooled in a sterile glass container. Sufficient plasma was then added to one acetate and one lactate solution to make a final concentration of $1 \mathrm{~g}$ of protein per litre; water was added with stirring to bring the four solutions to final concentration. The characteristics of the solutions are seen in Table I. The solutions were

TABLE I-Composition of the Dialysis Solutions

\begin{tabular}{|c|c|c|c|c|c|c|c|}
\hline \multirow{2}{*}{ With } & $\mathrm{Na}+$ & $\mathrm{Cl}-$ & $\mathrm{Ca}++$ & $\mathbf{M g}++$ & \multirow{2}{*}{$\underset{(\mathbf{g} / 1 .)}{\text { Glucose }}$} & \multirow{2}{*}{$\begin{array}{l}\text { Total } \\
\text { Protein } \\
\text { (g/l.) }\end{array}$} & \multirow{2}{*}{ pH } \\
\hline & \multicolumn{4}{|c|}{$\mathrm{mEq} / 1$. } & & & \\
\hline $\begin{array}{l}\text { Acetate . } \\
\text { Acetate and plasma } \\
\text { Lactate . } \\
\text { Lactate and plasma }\end{array}$ & $\begin{array}{l}137 \\
137 \\
137 \\
137\end{array}$ & $\begin{array}{c}100 \\
100 \\
98 * \\
98^{*}\end{array}$ & $\begin{array}{l}3 \\
3 \\
3 \\
3\end{array}$ & $\begin{array}{l}1.5 \\
1.5 \\
1.5 \\
1.5\end{array}$ & $\begin{array}{l}15 \\
15 \\
15 \\
15\end{array}$ & $\begin{array}{l}0 \\
1 \\
0 \\
1\end{array}$ & $\begin{array}{l}6 \cdot 8 \\
6 \cdot 8 \\
6 \cdot 8 \\
6 \cdot 8\end{array}$ \\
\hline
\end{tabular}

*About $2 \mathrm{mEq}$ of hydroxide was substituted for chloride to increase the pH of the solution.

sterilized by Seitz filtration and refrigerated in sterile glass containers. Their continued sterility was confirmed by cultures during the subsequent tests.

Fifteen different isolates of Staph. aureus, E. coli, and Pseudomonas sp. were obtained from clinical infections. Bacteria from each isolate were inoculated into $10 \mathrm{ml}$ of brainheart infusion broth and incubated at $35^{\circ} \mathrm{C}$ for 18 hours. A $0.01-\mathrm{ml}$ aliquot of each freshly incubated broth was inoculated into a 5-ml sample of each of the four kinds of dialysate. Dilutions of each broth culture in saline were streak-plated on tryptose agar to determine the numbers of viable bacteria in a $0.01 \mathrm{ml}$ inoculum. Both inoculated plates and dialysate were incubated for 18 hours at $35^{\circ} \mathrm{C}$. Aliquots from each tube of inoculated dialysate were diluted in saline and streak-plated on tryptose agar. After incubation at $35^{\circ} \mathrm{C}$ for 18 hours the colonies on these agar plates were counted and the number of viable organisms remaining in each $\mathrm{ml}$ of dialysate was established.

Paired comparisons of numbers of viable organisms from each isolate were used to compute $t$. The probability (P) that differences between mean numbers occurred by chance was derived from $t$. Means were considered significantly different when $P$ was less than 0.05 .

\section{Results}

The numbers of viable bacteria in the four solutions before and after incubation are shown in Table II. Incubation in the acetate solution completely killed the Staph. aureus from all 15 isolates (Table II). Incubation in the other three solutions caused smaller but significant decreases in numbers of staphylococci $(P<0.01)$. The difference between mean numbers of Staph. aureus after incubation in the lactate and acetate solutions which contained plasma was not significant.

The numbers of viable $E$. coli diminished $(P<0.1)$ during incubation in all four solutions (Table II). Incubation in the acetate solution without plasma completely sterilized 10 of the 15 isolates of $E$. coli and considerably reduced the numbers 
TABLE II-Numbers of Viable Bacteria per ml of Dialysate

\begin{tabular}{|c|c|c|c|c|c|}
\hline \multirow{2}{*}{ Isolate } & \multirow{2}{*}{$\begin{array}{c}\text { Before } \\
\text { Incubation }\end{array}$} & \multicolumn{4}{|c|}{ After Incubation } \\
\hline & & Acetate & $\begin{array}{l}\text { Acetate with } \\
\text { Plasma }\end{array}$ & Lactate & $\begin{array}{l}\text { Lactate with } \\
\text { Plasma }\end{array}$ \\
\hline \multicolumn{6}{|c|}{ Staphylococcus aureus } \\
\hline $\begin{array}{r}1 \\
2 \\
3 \\
4 \\
5 \\
6 \\
7 \\
8 \\
9 \\
10 \\
11 \\
12 \\
13 \\
14 \\
15\end{array}$ & $\begin{array}{l}1.5 \times 10^{4} \\
3.2 \times 10^{5} \\
4.7 \times 10^{5} \\
3.9 \times 10^{5} \\
4.8 \times 10^{5} \\
2.0 \times 10^{5} \\
4.1 \times 10^{5} \\
2.6 \times 10^{5} \\
9.5 \times 10^{5} \\
6.1 \times 10^{5} \\
7.0 \times 10^{5} \\
6.0 \times 10^{4} \\
1.6 \times 10^{8} \\
7.6 \times 10^{4} \\
2.0 \times 10^{4}\end{array}$ & $\begin{array}{l}0 \\
0 \\
0 \\
0 \\
0 \\
0 \\
0 \\
0 \\
0 \\
0 \\
0 \\
0 \\
0 \\
0 \\
0 \\
\end{array}$ & \begin{tabular}{|l|}
$6.0 \times 10^{1}$ \\
$4.8 \times 10^{3}$ \\
$1.5 \times 10^{4}$ \\
$1.1 \times 10^{4}$ \\
$2.3 \times 10^{4}$ \\
$1.0 \times 10^{4}$ \\
$2.2 \times 10^{4}$ \\
$3.0 \times 10^{4}$ \\
$1.3 \times 10^{4}$ \\
$2.0 \times 10^{4}$ \\
$4.0 \times 10^{4}$ \\
$6.0 \times 10^{1}$ \\
$4.8 \times 10^{3}$ \\
$1.5 \times 10^{4}$ \\
$2.9 \times 10^{4}$ \\
\end{tabular} & $\begin{array}{c}1.0 \times 10^{1} \\
5.0 \times 10^{4} \\
5.0 \times 10^{2} \\
0 \\
0 \\
1.0 \times 10^{1} \\
0 \\
0 \\
0 \\
1.5 \times 10^{4} \\
00 \\
1.0 \times 10^{1} \\
5.0 \times 10^{4} \\
5.0 \times 10^{1} \\
6.0 \times 10^{2} \\
\end{array}$ & $\begin{array}{c}2.0 \times 10^{1} \\
7.5 \times 10^{3} \\
4.0 \times 10^{4} \\
1.8 \times 10^{4} \\
1.4 \times 10^{4} \\
2.0 \times 10^{1} \\
7.5 \times 10^{3} \\
8.5 \times 10^{3} \\
3.0 \times 10^{3} \\
3.0 \times 10^{3} \\
2.9 \times 10^{4} \\
2.0 \times 10^{1} \\
7.5 \times 10^{3} \\
0 \\
0 \\
\end{array}$ \\
\hline Mean & $4.4 \times 10^{3}$ & 0 & $1.6 \times 10^{4}$ & $7 \cdot 7 \times 10^{3}$ & $9.2 \times 10^{3}$ \\
\hline \multicolumn{6}{|c|}{ Escherichia coli } \\
\hline $\begin{array}{r}1 \\
2 \\
3 \\
4 \\
5 \\
6 \\
7 \\
8 \\
9 \\
10 \\
11 \\
12 \\
13 \\
14 \\
15\end{array}$ & $\begin{array}{l}1.1 \times 10^{5} \\
1.7 \times 10^{5} \\
1.4 \times 10^{8} \\
1.7 \times 10^{6} \\
1.0 \times 10^{6} \\
1.0 \times 10^{6} \\
1.0 \times 10^{6} \\
1.2 \times 10^{6} \\
7.1 \times 10^{5} \\
8.0 \times 10^{5} \\
1.3 \times 10^{6} \\
4.1 \times 10^{8} \\
2.0 \times 10^{5} \\
8.0 \times 10^{5} \\
4.0 \times 10^{6}\end{array}$ & $\begin{array}{c}0 \\
0 \\
1.0 \times 10^{1} \\
0 \\
0 \\
0 \\
0 \\
0 \\
0 \\
0 \\
0 \\
1.5 \times 10^{3} \\
5.3 \times 10^{2} \\
1.8 \times 10^{2} \\
1.8 \times 10^{2} \\
\end{array}$ & \begin{tabular}{|l|}
$2.6 \times 10^{4}$ \\
$2.6 \times 10^{4}$ \\
$1.3 \times 10^{4}$ \\
$5.0 \times 10^{3}$ \\
$1.1 \times 10^{2}$ \\
$1.2 \times 10^{3}$ \\
$1.1 \times 10^{3}$ \\
$4.1 \times 10^{3}$ \\
$2.4 \times 10^{2}$ \\
$4.8 \times 10^{2}$ \\
$1.0 \times 10^{3}$ \\
$1.3 \times 10^{5}$ \\
$7.0 \times 10^{4}$ \\
$4.0 \times 10^{4}$ \\
$4.0 \times 10^{4}$ \\
\end{tabular} & $\begin{array}{l}1.7 \times 10^{3} \\
4.0 \times 10^{2} \\
6.2 \times 10^{2} \\
1.0 \times 10^{3} \\
7.0 \times 10^{2} \\
6.2 \times 10^{2} \\
1.2 \times 10^{3} \\
1.1 \times 10^{4} \\
1.2 \times 10^{3} \\
8.0 \times 10^{2} \\
2.1 \times 10^{3} \\
2.1 \times 10^{4} \\
1.8 \times 10^{3} \\
1.3 \times 10^{4} \\
1.3 \times 10^{4} \\
\end{array}$ & $\begin{array}{l}1.7 \times 10^{4} \\
2.2 \times 10^{4} \\
1.2 \times 10^{4} \\
1.3 \times 10^{4} \\
9.1 \times 10^{3} \\
1.9 \times 10^{3} \\
3.3 \times 10^{3} \\
1.2 \times 10^{4} \\
1.2 \times 10^{3} \\
2.0 \times 10^{1} \\
1.6 \times 10^{3} \\
5.0 \times 10^{3} \\
4.0 \times 10^{5} \\
7.0 \times 10^{5} \\
2.7 \times 10^{5}\end{array}$ \\
\hline$\overline{M e a n}$ & $1.2 \times 10^{6}$ & $1.6 \times 10^{2}$ & $2.4 \times 10^{4}$ & $4.7 \times 10^{3}$ & $9.8 \times 10^{4}$ \\
\hline \multicolumn{6}{|c|}{ Pseudomonas species } \\
\hline $\begin{array}{r}1 \\
2 \\
3 \\
4 \\
5 \\
6 \\
7 \\
8 \\
9 \\
10 \\
11 \\
12 \\
13 \\
14 \\
15 \\
\end{array}$ & $\begin{array}{l}1.6 \times 10^{5} \\
6.0 \times 10^{5} \\
4.0 \times 10^{5} \\
2.4 \times 10^{5} \\
6.0 \times 10^{5} \\
3.8 \times 10^{5} \\
7.4 \times 10^{5} \\
1.2 \times 10^{5} \\
4.0 \times 10^{6} \\
1.4 \times 10^{4} \\
1.0 \times 10^{4} \\
5.0 \times 10^{3} \\
4.0 \times 10^{2} \\
2.0 \times 10^{3} \\
2.0 \times 10^{4}\end{array}$ & $\begin{array}{l}1.0 \times 10^{2} \\
1.0 \times 10^{5} \\
6.0 \times 10^{2} \\
8.0 \times 10^{2} \\
6.0 \times 10^{3} \\
1.8 \times 10^{5} \\
1.6 \times 10^{5} \\
2.8 \times 10^{5} \\
1.0 \times 10^{3} \\
5.0 \times 10^{8} \\
2.5 \times 10^{6} \\
3.1 \times 10^{6} \\
5.6 \times 10^{6} \\
7.0 \times 10^{3} \\
4.6 \times 10^{6} \\
\end{array}$ & \begin{tabular}{|l}
$1.2 \times 10^{5}$ \\
$8.0 \times 10^{6}$ \\
$5.0 \times 10^{6}$ \\
$8.3 \times 10^{6}$ \\
$5.0 \times 10^{6}$ \\
$1.5 \times 10^{7}$ \\
$4.4 \times 10^{8}$ \\
$3.6 \times 10^{6}$ \\
$4.0 \times 10^{6}$ \\
$1.5 \times 10^{6}$ \\
$5.0 \times 10^{6}$ \\
$4.5 \times 10^{7}$ \\
$4.8 \times 10^{5}$ \\
$6.8 \times 10^{4}$ \\
$1.0 \times 10^{6}$ \\
\end{tabular} & $\begin{array}{l}1.8 \times 10^{6} \\
1.9 \times 10^{5} \\
3.9 \times 10^{6} \\
5.0 \times 10^{8} \\
3.9 \times 10^{6} \\
1.6 \times 10^{7} \\
4.0 \times 10^{6} \\
5.0 \times 10^{6} \\
5.0 \times 10^{6} \\
5.0 \times 10^{6} \\
3.0 \times 10^{6} \\
3.7 \times 10^{7} \\
9.2 \times 10^{6} \\
5.6 \times 10^{4} \\
1.0 \times 10^{8}\end{array}$ & $\begin{array}{l}2.4 \times 10^{6} \\
1.8 \times 10^{7} \\
4.0 \times 10^{2} \\
1.0 \times 10^{3} \\
4.0 \times 10^{2} \\
6.0 \times 10^{3} \\
1.0 \times 10^{4} \\
3.8 \times 10^{4} \\
1.0 \times 10^{3} \\
6.0 \times 10^{6} \\
1.0 \times 10^{2} \\
8.7 \times 10^{7} \\
4.0 \times 10^{8} \\
1.0 \times 10^{2} \\
1.0 \times 10^{8} \\
\end{array}$ \\
\hline Mean & $2.5 \times 10^{5}$ & $1.4 \times 10^{6}$ & $7 \cdot 1 \times 10^{6}$ & $1.3 \times 10^{7}$ & $1.4 \times 10^{7}$ \\
\hline
\end{tabular}

from the other five. Fewer live $E$. coli remained in this acetate solution than in the plain lactate $(P<0.02)$ or in the acetate with plasma $(P<0.05)$ solution. In the comparison of acetate and lactate solutions which contained plasma the difference between mean numbers of viable $E$. coli after incubation was not significant.

The mean numbers of Pseudomonas sp. increased during incubation in all four fluids (Table II). Only in the acetate with plasma solution was this increase from the original number significant $(P<0.05)$. In the comparisons of the four solutions after incubation no significant difference occurred between mean numbers of viable Pseudomonas sp.

\section{Discussion}

Widespread use in recent years of small tightly-fitting stylet catheters and dialysis for only one or two days at a time has decreased the incidence of peritonitis from peritoneal dialysis (Schwartz et al., 1967). Most likely this improvement results from a smaller site of entry for bacteria from the skin and a shorter time for infection to occur from skin or across the intestinal wall. Since changing several years ago to the small catheters and a relatively closed system for dispensing and collecting fluids, we have seen no peritonitis in over 300 dialyses (Richardson et al., 1968). During this time we also changed to a dialysis fluid which contained acetate rather than the lactate, which is the source of base in most proprietary solutions. The complete disappearance of peritonitis raised the question of a greater antibacterial effect of the ace- tate. In an earlier experiment with Staph. aureus, E. coli, and Pseudomonas sp. incubation in dialysis solutions which contained acetate rather than lactate did result in a reduction in viable organisms (Richardson and Borchardt, 1969). These results gave hope that acetate solutions might confer greater protection from peritonitis than the commonly used lactate solutions.

In the earlier experiment the dialysate in which the bacteria were incubated contained no source of nitrogen. During peritoneal dialysis proteins and smaller nitrogenous substances, such as amino-acids, diffuse into the dialysate. Concentrations of protein in dialysate at the end of each hour's fluid cycle vary widely among patients. A gramme of total protein per litre of returning fluids, however, is representative of the protein found in returned dialysate by several different investigators (Berlyne et al., 1964; Gordon and Rubini, 1967) and is the concentration of plasma protein used in our test solutions.

Dialysate effluent contains all the usual protein fractions in proportions only slightly different from those of serum (Berlyne et al., 1964; Gordon and Rubini, 1967). The addition of plasma to our test solution, then, provided a model of dialysate effluent whose content of protein was similar to that commonly found in dialysate effluent and whose content of salt and glucose could be easily controlled. Our final concentrations of smaller, more readily diffusible nitrogen compounds, such as amino-acids, were almost certainly less than those likely to be found in peritoneal fluids during dialysis (Berlyne et al., 1967).

Incubation of bacteria in the acetate and lactate dialysates which contained no plasma gave results similar to our earlier study, also done with clinical isolates. The bactericidal effect of the acetate solution on Staph. aureus and E. coli was greater than before. A mildly adverse effect of the acetate solution on Pseudomonas sp., however, was not seen this time. The bacteria were, of course, from different infections, and the differences which did appear probably represent variability among strains of bacteria.

The addition of plasma to both the acetate and the lactate solutions diminished but did not eliminate their adverse effect on Staph. aureus and E. coli. At the concentration of plasma used the greater antibacterial effect of acetate on these bacteria disappeared. For most of the strains of Pseudomonas sp. the addition of plasma to the lactate and acetate solutions did not make particularly better growth media.

Even an intermittent antibacterial effect of dialysate could protect from peritonitis. Our results suggest that solutions made with acetate rather than lactate will not exert a greater antibacterial effect throughout all of each one-hour cycle. Every new batch of solution, however, dilutes the substances which have diffused into the peritoneal fluid during the preceding exchange. Therefore, the greater antibacterial effect of acetate for Staph. aureus and E. coli may exist in the more dilute fluids immediately after each change of dialysate. Incubation of bacteria in peritoneal fluid aspirated at intervals within each cycle of dialysis will be necessary to prove such an intermittent benefit of acetate solution.

This project was supported by Grant AM 10642, National Institutes of Health, Bethesda, Maryland.

\section{References}

Berlyne, G. M., Jones, J. H., Hewitt, V., and Nilwarangkur, S. (1964) Lancet, $1,738$.

Berlyne, G. M., Lee, H. A., Giordano, C., De Pascale, C., and Esposito, R. (1967). Lancet, 1, 1339.

Gordon, S., and Rubini, M. E. (1967). American fournal of the Medical Sciences, 253, 284.

Richardson, J. A., and Borchardt, K. A. (1969). British Medical fournal, 3,

749.
Richardson, J. A., Philbin, P. E., and Herron, G. R. (1968). British Medical fournal, 4, 757 .

Schwartz, F. D., Kallmyer, J., Dunea, G., and Kark, R. M. (1967). Fournal of the American Medical Association, 199, 79. 